\title{
Discovery of DiPeptidyl Peptidase-4 Gene Variants and the Associations with Efficacy of Vildagliptin in Patients with Type 2 Diabetes - A Pilot Study
}

Obin Kwon ${ }^{1,2}$, Eun Yeong Choe ${ }^{3}$, Younjeong Choi ${ }^{3}$, Hyun Min Kim³ ${ }^{3}$ Hye Jin Wang ${ }^{2,4}$, Hyangkyu Lee ${ }^{5}$, Chul Hoon Kim ${ }^{1,2}$ and Eun Seok Kang ${ }^{2-4 *}$

${ }^{1}$ Department of Pharmacology, Yonsei University College of Medicine, Korea

${ }^{2}$ Brain Korea 21 Project for Medical Science, Yonsei University College of Medicine, Korea

${ }^{3}$ Division of Endocrinology and Metabolism, Department of Internal Medicine, Yonsei University College of Medicine, Korea

${ }^{4}$ Institute of Endocrine Research, Yonsei University College of Medicine, Korea

${ }^{5}$ Department of Clinical Nursing Science, Yonsei University College of Nursing, Korea

\begin{abstract}
Background: The dipeptidyl peptidase-4 (DPP4) inhibitors have become widely used antidiabetic medication They control glycemia by interacting with serum DPP4 to interfere catalyzation of incretins. The aim of this pilot study was to discover the DPP4 polymorphisms that could affect the efficacy of vildagliptin, a DPP-4 inhibitor in diabetic patients.

Methods: Genetic variations in DPP4 were identified in 48 patients with type 2 diabetes who received vildagliptin treatment at least 12 weeks following metformin monotherapy. Luciferase assay was performed to estimate the effect of the regulatory single nucleotide polymorphism (SNP) on expression of DPP4.

Results: Eight tagging SNPs were genotyped in a sample of 24 patients. Additional sample of 24 patients was used to discover further regulatory SNPs and coding SNPs. In all 48 patients, responders (degree of HbA1c and/or fasting glucose level decrease greater than $10 \%$ of baseline after 12 weeks of vildagliptin add-on treatment) did not show any significant difference in selected six DPP4 polymorphisms from non-responders. DPP4 expression was not different according to g.-234A/C in luciferase assay.
\end{abstract}

Conclusion: Our pilot study could not find any significant genetic variant which is associated with vildagliptin response in patients with type 2 diabetes. Further studies in large population are warranted.

Keywords: Dipeptidyl Peptidase-4; Single nucleotide polymorphism; Vildagliptin

\section{Introduction}

Diabetes mellitus is growing global pandemic [1], causing microand macrovascular complications [2]. Compared with type 1 diabetes due to an absolute deficiency of insulin secretion, type 2 diabetes, a much more prevalent category, is due to combination of resistance to insulin action and an inadequate compensatory insulin secretory response [3]. Metformin is the preferred initial pharmacological agent for type 2 diabetes, and if metformin monotherapy at maximal tolerated dose does not achieve or maintain the hemoglobin A1c (HbA1c) target over 3-6 months, a second agent is needed to control glycemia. Among the option of add-on therapy is dipeptidyl peptidase-4 (DPP4) inhibitor [4,5]. DPP4 inhibitors have few side effects, and their prescriptions have been increasing [6]

Oral glucose intake induces glucagon-like peptide-1 (GLP-1) and gastric inhibitory polypeptide (GIP), which are insulinotropic depending on glucose level. DPP4 deactivates bioactive peptides, including GLP-1 and GIP. DPP4 inhibitors bind to this DPP4 and control glycemic surge after meal by enhancing the action of GLP-1 and GIP, consequently [7]. Therefore, the efficacy of DPP4 inhibitors might be affected if the expression level of DPP4 is changed or if the altered structure of DPP4 affects the affinity with DPP4 inhibitors. However, there has been no study which analyzed the association between DPP4 polymorphism with the efficacy of DPP4 inhibitors discovered so far. Given these points, we discovered DPP4 single nucleotide polymorphisms (SNPs) in Korean population and searched for polymorphisms that affect the efficacy of vildagliptin, a member of DPP4 inhibitor group.

\section{Materials and Methods}

\section{Subjects}

A total of 48 patients with type 2 diabetes mellitus were recruited from the outpatient clinics at Yonsei University Severance Hospital Diabetes Center, Seoul, Korea. For this study, type 2 diabetes mellitus was defined according to the American Diabetes Association criteria [3]. Patients who had received metformin monotherapy and whose $\mathrm{HbAlc}$ values ranged from $6 \%$ to $8 \%$ were enrolled. All patients were treated with vildagliptin for at least 12 weeks as add-on therapy following metformin monotherapy. All enrolled patients took $50 \mathrm{mg}$ vildagliptin daily (as a q.d. dose) or $100 \mathrm{mg}$ vildagliptin daily (as equally divided doses). The inclusion criteria were as follows: (1) age 20 to 90

${ }^{*}$ Corresponding author: Eun Seok Kang, Department of Internal Medicine, Yonsei University College of Medicine, Seoul 120-752, Korea, Tel: +82-2-2228-1968; Fax: +82-2-393-6884; E-mail: edgo@yuhs.ac

Received May 31, 2013; Accepted June 26, 2013; Published June 30, 2013

Citation: Kwon O, Choe EY, Choi Y, Kim HM, Wang HJ, et al. (2013) Discovery of DiPeptidyl Peptidase-4 Gene Variants and the Associations with Efficacy of Vildagliptin in Patients with Type 2 Diabetes - A Pilot Study. J Diabetes Metab S13: 006. doi:10.4172/2155-6156.S13-006

Copyright: ( $2013 \mathrm{Kwon}$ O, et al. This is an open-access article distributed unde the terms of the Creative Commons Attribution License, which permits unrestricted use, distribution, and reproduction in any medium, provided the original author and source are credited. 
Citation: Kwon O, Choe EY, Choi Y, Kim HM, Wang HJ, et al. (2013) Discovery of DiPeptidyl Peptidase-4 Gene Variants and the Associations with Efficacy of Vildagliptin in Patients with Type 2 Diabetes - A Pilot Study. J Diabetes Metab S13: 006. doi:10.4172/2155-6156.S13-006

Page 2 of 6

years, (2) no previous history of DPP4 inhibitor use, (3) no medication change in the last 3 months, and (4) for women, postmenopause or use of appropriate contraceptive methods. Patients with type 1 diabetes, a history of ketoacidosis, ischemic heart disease, or congestive heart failure (New York Heart Association class II-IV), and pregnant or lactating women were excluded from this study. Response to vildagliptin add-on treatment was defined by modification of criteria suggested by Blüher et al. [8]. Responders were defined as a greater than $10 \%$ decrease in HbA1c values or fasting plasma glucose (FPG) levels (or both) after 12 weeks of vildagliptin treatment. Non-responders were defined as those patients who did not meet these criteria. This pilot study protocol was approved by the Institutional Review Board of Yonsei University College of Medicine, Seoul, Korea (4-2011-0912), and all subjects provided written informed consent.

\section{Study assessments}

FPG, 2-hour postprandial plasma glucose (PPG), and HbAlc were assessed initially and during two additional visits, at weeks 12 and 24 of treatment. Body mass index (BMI), standard biochemistry laboratory profile and fasting plasma insulin level before initial administration of vildagliptin were collected. Initial homeostatic model assessment of insulin resistance (HOMA-IR) and homeostatic model assessment of beta-cell function (HOMA-B) were calculated. Genomic DNA was isolated from peripheral blood lymphocytes.

\section{Gene scanning}

Gene scanning was performed to discover DPP4 polymorphisms prevalent in the Korean diabetes population. For initial discovery, 24 diabetic patients were recruited. A promoter region $-2.6 \mathrm{~kb}$ from the translation initiation site, the entire coding exons, and flanking intronic sequences of the DPP4 gene were amplified in 28 polymerase chain reaction (PCR) fragments and sequenced by an automated genetic analyzer (Model 3730xl,Applied Biosystems, Foster City, CA). Haplotype analysis was performed using the Haploview 4.1 program based on a standard expectation-maximization algorithm to construct haplotype blocks. For further discovery of regulatory SNPs (rSNPs) and coding SNPs (cSNPs), 24 additional diabetic patients were recruited. DPP4 gene was amplified in 9 PCR fragments and sequenced targeting rSNPs and 17 non-synonymous SNPs (nsSNPs) that were predicted as possible impact on the structure and function of DPP4 protein by Polyphen-2 [9] and/or SIFT [10].

\section{Measurements of DPP4 promoter activity in vitro}

To construct the reporter plasmids containing human DPP4 promoter region, a 477-bp fragment of human DPP4 (-507 to -31 relative to the translation initiation site) was amplified with DNA samples from homozygotes with DPP4 g.-234C or g.-234A. Manufacture of this fragment was modified from the construct which had showed the most luciferase activity in previous study by Böhm et al.[11]. The amplified products were inserted into pGL3-basicluciferase reporter vectors (Promega Corporation, Madison, WI) using restriction enzyme sites and DNA sequences were confirmed by dideoxynucleotide-based sequencing.

Caco-2 cells originated from human colorectal adenocarcinoma were cultured in Dulbecco's modified Eagle's medium formulated with $4500 \mathrm{mg} / \mathrm{L}$ glucose, supplemented with $20 \%$ fetal bovine serum, $100 \mathrm{U} / \mathrm{mL}$ penicillin $\mathrm{G}$, and $100 \mathrm{mg} / \mathrm{mL}$ streptomycin. ThepGL3basicplasmidscontaining DPP4 promoters and control Renilla luciferase vectors were co-transfected into Caco-2 cells using jetPRIME (Polyplus transfection, Illkirch, France). Luciferase assays were performed using
Dual-Luciferase Reporter Assay System (Promega) according to the manufacturer's instructions. Light emission was measured using a microplate luminometer (Berthold Technologies, Wildbad, Germany).

\section{In silico identification of putative transcription factor binding sites in DPP4 promoter sequences}

To identify putative transcription factor binding site in DPP4 promoter sequences, the DPP4 sequences around g.-234 site were analyzed using two different transcription factor binding site prediction programs, PROMO 3.0.2 [12] and MatInspector from Genomatix Software Suite [13].

\section{Statistical analysis}

Statistical analysis was performed using IBM SPSS Statistics 20 (IBM Corp. Armonk, NY) and Graphpad Prism 5.0 (Graphpad Software, Inc., San Diego, CA) software packages. Differences between responder and non-responder groups were tested by use of chi-square tests or $t$-tests for categorical and continuous variables, respectively. Genotype/allele frequency comparisons between responder and nonresponder groups were performed by chi-square tests. Fisher's exact test was used if expected cell frequencies were lower than 5. Multivariate logistic regression was performed to evaluate the major determinants of vildagliptin response. Genotype frequencies at each SNP were tested for Hardy-Weinberg equilibrium. All P values were based on two-sided comparisons and $\mathrm{P}$ values less than 0.05 were considered statistically significant.

\section{Results}

The baseline characteristics of the 35 responder and 13 nonresponder subjects are presented in Table 1 . There were no statistical differences in baseline characteristics between the two groups, including FPG, 2-hour PPG, and HbA1c. After 3 months of add-on therapy, the degree of HbAlc and/or FPG level decrease was significantly greater in the responder group than in the non-responder group $(\mathrm{P}<0.001$, respectively). After 6 months of add-on therapy, HbAlc was still maintained significantly lower in responder group $(\mathrm{P}<0.001)$

To discover DPP4 polymorphisms, dideoxynucleotide-based DNA sequencing was performed using samples derived from twenty-four type 2 diabetic patients. A total of 14 genetic variations were discovered after comprehensive gene scanning, covering all exons, exon-intron junctions and a promoter region up to $2.6 \mathrm{~kb}$ from the translation initiation site. No nsSNP was discovered in enrolled patients. The linkage-disequilibrium (LD) structure of the DPP4 gene is shown in Figure 1. Of the 14 variations, two with an allele frequency less than $5 \%$ were excluded from further analyses. Finally, eight tagging SNPs were selected for DPP4 genotyping as detailed in Materials and Methods.

To discover SNPs affecting the efficacy of vildagliptin, 24 additional diabetic patients were recruited. Targeted SNPs were rSNPs within 500 base pairs from starting codon and 17 nsSNPs predicted as possible impact on the structure and function of DPP4 protein. Synonymous SNP (sSNP) G645G (rs17848910), rSNPg.-234A/C (rs13015258) and other intervening sequences (IVSs) were discovered in this step. No nsSNP was discovered. To evaluate whether DPP4 genetic variations are associated with glucose-lowering effect of vildagliptin, a casecontrol association analysis was performed using genotype data on the 6 SNPs, including G645G andg.-234A/C. (Table 2). The genotype distributions of all SNPs were in accordance with Hardy-Weinberg equilibrium $(\mathrm{P}>0.05)$ in each set of samples. Of the six SNPs tested, there was no SNP strongly associated with efficacy of vildagliptin. 
Citation: Kwon O, Choe EY, Choi Y, Kim HM, Wang HJ, et al. (2013) Discovery of DiPeptidyl Peptidase-4 Gene Variants and the Associations with Efficacy of Vildagliptin in Patients with Type 2 Diabetes - A Pilot Study. J Diabetes Metab S13: 006. doi:10.4172/2155-6156.S13-006

Page 3 of 6

Multivariate logistic regression analyses were performed to define the major determinants for vildagliptin treatment response and to reveal other parameters influencing the response rate. No SNPs were found to be a major determinant of response rate (Table 3). Multiple logistic regression analyses revealed that baseline $\mathrm{HbAlc}$ was the major confounding factor of therapeutic response to vildagliptin.

To measure the promoter activity of DPP4 according to rSNP g.$234 \mathrm{~A} / \mathrm{C}$, reporter constructs containing the rSNP were constructed and their transcriptional activities were measured in Caco-2 cells. The transcriptional activities of major allele and minor $\mathrm{C}$ allele showed no significant difference (Figure 2).

\section{Discussion}

In this study, we examined the effects of the polymorphisms of the DPP4 gene on the response to vildagliptin in Korean patients with type 2 diabetes mellitus. The results of this pilot study do not support the notion that DPP4 polymorphisms modulate the efficacy of DPP4 inhibitors among diabetic patients. In the first screening of DPP4 polymorphisms from 24 diabetic patients, we failed to discover nsSNPs that may possibly impact the structure and function of DPP4 protein in Korean population. There was no nsSNP found in the second set of samples from other 24 diabetic patients, either. Only sSNP G645G showed a modest $\mathrm{P}$ value of 0.175 in multivariate logistic regression of response to vildagliptin add-on therapy, which leaves room for possibility of association with increased number of subjects enrolled. Instead, the multiple logistic regression tests revealed that baseline $\mathrm{HbA1c}$ was the major confounding factor of therapeutic response to vildagliptin add-on: in other words, the efficacy of vildagliptin add-on is less to relatively well-controlled diabetic patients.

Regulatory SNP g.-234A/C discovered in this study did not influence the efficacy of vildagliptin in clinical data and in vitro study. To identify potential transcriptional elements that might be involved in regulating the transcriptional activity of DPP4 in silico, sequences around g.-234A/C were analyzed using two different transcription

\begin{tabular}{|c|c|c|c|c|c|}
\hline \multirow{2}{*}{\begin{tabular}{|l|} 
Characteristic \\
No. of subjects
\end{tabular}} & \multicolumn{2}{|c|}{ Responder } & \multicolumn{2}{|c|}{ Non-responder } & \multirow[t]{2}{*}{$P$ value } \\
\hline & 35 & $(72.9)$ & 13 & $(27.1)$ & \\
\hline Male & 15 & $(42.9)$ & 6 & $(46.2)$ & 0.838 \\
\hline Age (year) & 60.4 & $(12.4)$ & 57.4 & $(10.1)$ & 0.441 \\
\hline Body mass index $\left(\mathrm{kg} / \mathrm{m}^{2}\right)$ & 25.01 & $(3.72)$ & 26.24 & $(3.56)$ & 0.344 \\
\hline Duration of diabetes (year) & 7.54 & $(5.17)$ & 8.85 & $(4.96)$ & 0.437 \\
\hline \multicolumn{6}{|l|}{ Baseline } \\
\hline FPG (mmol/L) & 6.79 & $(1.05)$ & 6.80 & $(0.79)$ & 0.980 \\
\hline 2-hour PPG (mmol/L) & 10.73 & $(2.84)$ & 11.03 & $(2.04)$ & 0.737 \\
\hline $\mathrm{HbA} 1 \mathrm{c}(\%)$ & 7.25 & $(0.40)$ & 7.00 & $(0.42)$ & 0.059 \\
\hline Fasting plasma insulin (pmol/L) & 90.42 & $(79.03)$ & 48.27 & $(17.15)$ & 0.214 \\
\hline Blood urea nitrogen (mmol/L) & 5.22 & $(1.25)$ & 4.97 & $(1.66)$ & 0.568 \\
\hline Creatinine $(\mu \mathrm{mol} / \mathrm{L})$ & 72.49 & $(13.26)$ & 81.33 & (15.91) & 0.065 \\
\hline eGFR $\left(\mathrm{mL} / \mathrm{min} / 1.73 \mathrm{~m}^{2}\right)$ & 89.94 & $(15.27)$ & 82.50 & $(15.93)$ & 0.156 \\
\hline Aspartate aminotransferase (IU/L) & 20.34 & $(10.87)$ & 22.62 & $(7.47)$ & 0.492 \\
\hline Alanine aminotransferase (IU/L) & 24.00 & $(18.69)$ & 24.85 & $(12.32)$ & 0.881 \\
\hline Total cholesterol (mmol/L) & 4.47 & $(0.76)$ & 4.51 & $(0.89)$ & 0.902 \\
\hline HDL cholesterol (mmol/L) & 1.23 & $(0.27)$ & 1.21 & $(0.26)$ & 0.819 \\
\hline LDL cholesterol (mmol/L) & 2.59 & $(0.68)$ & 2.51 & $(0.82)$ & 0.759 \\
\hline Triglyceride $(\mathrm{mmol} / \mathrm{L})$ & 1.41 & $(0.59)$ & 1.78 & $(0.50)$ & 0.056 \\
\hline HOMA-B & 105.52 & $(141.48)$ & 46.77 & $(23.61)$ & 0.329 \\
\hline HOMA-IR & 3.60 & $(2.70)$ & 2.06 & $(0.66)$ & 0.185 \\
\hline Dose of daily metformin (mg) & 945.71 & $(392.65)$ & 976.92 & $(454.89)$ & 0.816 \\
\hline Dose of daily vildagliptin (mg) & 87.14 & $(22.17)$ & 84.62 & $(24.02)$ & 0.733 \\
\hline \multicolumn{6}{|l|}{3 month after Vildagliptin administration } \\
\hline $\mathrm{FPG}(\mathrm{mmol} / \mathrm{L})$ & 6.06 & $(1.00)$ & 7.42 & $(1.29)$ & $<0.001$ \\
\hline$\triangle \mathrm{FPG}(\mathrm{mmol} / \mathrm{L})$ & -0.73 & $(0.92)$ & 0.62 & $(1.13)$ & $<0.001$ \\
\hline 2-hour PPG (mmol/L) & 8.34 & $(2.28)$ & 10.08 & $(2.81)$ & 0.035 \\
\hline$\Delta 2$-hour PPG (mmol/L) & -2.43 & $(2.89)$ & -1.40 & $(1.40)$ & 0.117 \\
\hline $\mathrm{HbA} 1 \mathrm{c}(\%)$ & 6.26 & $(0.44)$ & 6.87 & $(0.59)$ & $<0.001$ \\
\hline$\Delta \mathrm{HbA} 1 \mathrm{c}(\%)$ & -0.99 & $(0.32)$ & -0.13 & $(0.51)$ & $<0.001$ \\
\hline \multicolumn{6}{|l|}{6 month after Vildagliptin administration } \\
\hline $\mathrm{FPG}(\mathrm{mmol} / \mathrm{L})$ & 6.24 & $(1.00)$ & 6.89 & $(1.29)$ & 0.098 \\
\hline$\Delta \mathrm{FPG}(\mathrm{mmol} / \mathrm{L})$ & -0.59 & $(0.90)$ & 0.10 & $(0.81)$ & 0.024 \\
\hline 2-hour PPG (mmol/L) & 8.66 & $(2.28)$ & 10.63 & $(2.81)$ & 0.024 \\
\hline$\Delta 2$-hour PPG (mmol/L) & -2.07 & $(2.65)$ & -0.39 & $(2.71)$ & 0.074 \\
\hline $\mathrm{HbA} 1 \mathrm{c}(\%)$ & 6.28 & $(0.32)$ & 6.80 & $(0.68)$ & 0.003 \\
\hline$\Delta \mathrm{HbA} 1 \mathrm{c}(\%)$ & -0.97 & $(0.42)$ & -0.20 & $(0.41)$ & $<0.001$ \\
\hline
\end{tabular}

Results expressed as $n(\%)$ or mean values (SD). Chi-square test or t-test was used for $P$ value where appropriate. $\Delta$ means the difference from baseline level. Abbreviations: FPG: Fasting Plasma Glucose; PPG: Postprandial Plasma Glucose; eGFR: Estimated Glomerular Filtration Rate; HDL: High Density Lipoprotein; LDL: Low Density Lipoprotein; HOMA-B: Homeostatic Model Assessment of Beta Cell Function; HOMA-IR: Homeostatic Model Assessment of Insulin Resistance

Table 1: Characteristics of the 48subjects according to response to vildagliptin add-on therapy. 
Citation: Kwon O, Choe EY, Choi Y, Kim HM, Wang HJ, et al. (2013) Discovery of DiPeptidyl Peptidase-4 Gene Variants and the Associations with Efficacy of Vildagliptin in Patients with Type 2 Diabetes - A Pilot Study. J Diabetes Metab S13: 006. doi:10.4172/2155-6156.S13-006

Page 4 of 6

\begin{tabular}{|c|c|c|c|c|c|c|c|c|c|c|c|}
\hline \multirow{3}{*}{$\begin{array}{c}\text { SNP } \\
\text { g.-234A/C }\end{array}$} & \multirow{3}{*}{$\begin{array}{c}\text { Genotype } \\
\text { A/A }\end{array}$} & \multicolumn{4}{|c|}{ Group n (\%) } & \multirow{3}{*}{$\begin{array}{c}\text { Allele } \\
\text { A }\end{array}$} & \multicolumn{4}{|c|}{ Group n (\%) } & \multirow{3}{*}{$\begin{array}{c}\text { P value } \\
0.590\end{array}$} \\
\hline & & \multicolumn{2}{|c|}{ Responder } & \multicolumn{2}{|c|}{ Non-responder } & & \multicolumn{2}{|c|}{ Responder } & \multicolumn{2}{|c|}{ Non-responder } & \\
\hline & & 16 & $(45.7)$ & 8 & (61.5) & & 50 & $(71.4)$ & 20 & (76.9) & \\
\hline \multirow{2}{*}{ (rs13015258) } & $\mathrm{A} / \mathrm{C}$ & 18 & (51.4) & 4 & $(30.8)$ & C & 20 & (28.6) & 6 & (23.1) & \\
\hline & $\mathrm{C} / \mathrm{C}$ & 1 & (2.9) & 1 & $(7.7)$ & & & & & & \\
\hline IVS8-128A/G & $\mathrm{G} / \mathrm{G}$ & 31 & (88.6) & 11 & (84.6) & G & 66 & $(94.3)$ & 24 & (92.3) & 0.661 \\
\hline (rs17848920) & $\mathrm{G} / \mathrm{A}$ & 4 & (11.4) & 2 & (15.4) & A & 4 & $(5.7)$ & 2 & $(7.7)$ & \\
\hline IVS8+46C/T & $\mathrm{C} / \mathrm{C}$ & 18 & (51.4) & 5 & (38.5) & C & 51 & (72.9) & 17 & $(65.4)$ & 0.474 \\
\hline \multirow[t]{2}{*}{ (rs10930040) } & $\mathrm{C} / \mathrm{T}$ & 15 & $(42.9)$ & 7 & (53.8) & $\mathrm{T}$ & 19 & (27.1) & 9 & $(34.6)$ & \\
\hline & $T / T$ & 2 & (5.7) & 1 & (7.7) & & & & & & \\
\hline $\begin{array}{l}\text { IVS11- } \\
143 \mathrm{~A} / \mathrm{G}^{*}\end{array}$ & $\mathrm{G} / \mathrm{G}$ & 20 & $(57.1)$ & 5 & $(38.5)$ & G & 51 & (72.9) & 17 & $(65.4)$ & 0.474 \\
\hline \multirow[t]{2}{*}{ (rs2302873) } & $\mathrm{G} / \mathrm{A}$ & 11 & (31.4) & 7 & $(53.8)$ & A & 19 & (27.1) & 9 & (34.6) & \\
\hline & $\mathrm{A} / \mathrm{A}$ & 4 & (11.4) & 1 & $(7.7)$ & & & & & & \\
\hline G645G & $\mathrm{C} / \mathrm{C}$ & 25 & $(73.5)$ & 12 & (92.3) & C & 59 & $(86.8)$ & 25 & $(96.2)$ & 0.275 \\
\hline (rs17848910) & $\mathrm{C} / \mathrm{T}$ & 9 & $(26.5)$ & 1 & $(7.7)$ & T & 9 & $(13.1)$ & 1 & $(3.8)$ & \\
\hline IVS22+4C/T & $T / T$ & 31 & $(91.2)$ & 10 & (76.9) & T & 65 & (95.6) & 23 & (88.5) & 0.342 \\
\hline (rs2268891) & $T / C$ & 3 & $(8.8)$ & 3 & (23.1) & C & 3 & $(4.4)$ & 3 & (11.5) & \\
\hline
\end{tabular}

Nucleotide location number of SNP was assigned according to the DPP4 mRNA sequence (GenBank accession number: NM_001935.3). In comparison between alleles,

$P$ values were obtained by using Chi-square test or Fisher's exact test (expected cell value $<5$ ).

Abbreviations: IVS: Intervening Sequence; SNP: Single Nucleotide Polymorphism. " Linkage with rs 10930040

Table 2: Frequency of DPP4 genetic variations in diabetic patients according to response to vildagliptin add-on therapy.

A. g.-234A/C genotype of DPP4

\begin{tabular}{|c|c|c|}
\hline Variable & OR & $\mathbf{~ ( 9 5 \% ~ C I ) ~}$ \\
\hline Gender $(0=$ male, $1=$ female) & 0.87 & $(0.264-2.871)$ \\
\hline Age & 0.97 & $(0.925-1.018)$ \\
\hline Body mass index & 1.05 & $(0.894-1.233)$ \\
\hline Duration of diabetes & 1.06 & $(0.930-1.206)$ \\
\hline HbA1c & 0.05 & $(0.008-0.273)$ \\
\hline g.-234A/C allele $(0=A, 1=C)$ & 0.52 & $(0.145-1.900)$ \\
\hline
\end{tabular}

B. G645G genotype of DPP4

\begin{tabular}{|c|c|c|}
\hline Variable & OR & $(95 \%$ Cl) \\
\hline Gender $(0=$ male, $1=$ female) & 0.78 & $(0.223-2.717)$ \\
\hline Age & 0.97 & $(0.927-1.021)$ \\
\hline Body mass index & 1.05 & $(0.887-1.240)$ \\
\hline Duration of diabetes & 1.06 & $(0.928-1.216)$ \\
\hline HbA1c & 0.04 & 0.267 \\
\hline G645G allele $(0=C, 1=T)$ & 0.19 & 0.575 \\
\hline
\end{tabular}

OR: Odds Ratio; Cl: Confidence Interval

Table 3: Multivariate logistic regression analyses for influence of clinical and biochemical factors on response to vildagliptin treatment.

factor binding site prediction programs (Supplement File).The results showed some different putative transcriptional elements between genotypes for dissimilarity percentage and random expectation (RE; the lower dissimilarity and/or RE value, the more reliable the hit), which might be false positive (Table 1) [14]. Other methods including electrophoretic mobility shift assay (EMSA) and correlation with DPP4 concentration in blood sample can help to discriminate potential binding of transcriptional elements.

DPP4 is the key enzyme responsible for cleaving and inactivating both GLP-1 and GIP at the penultimate alanine residue [15]. To inhibit this inactivation, two drug classes based on their structure have been developed as DPP4 inhibitors: peptidomimetics that mimic the DPP4 molecule (ex. vildagliptin and saxagliptin) and non-peptidomimetics (ex. sitagliptin and linagliptin). When peptidomimetics bind to DPP4, they dissociate slowly resulting in persistent inhibition of DPP4 even after inactivation, although they are cleared from the plasma relatively quickly. In contrast, non-peptidomimetics form noncovalent interactions with residues in the catalytic site, which result in immediate and potent inhibition [16]. In these contexts, DPP4 nsSNPs that have impact on the structure and function of DPP4 protein may exert greater effect on the efficacy of sitagliptin or linagliptin compared to vildagliptin or saxagliptin because of its influence on the binding affinity. Moreover, the effect on the expression level of DPP4 protein according to DPP4 rSNPs might be different between the two classes of DPP4 inhibitors. These points leave room for further pharmacogenetic study of DPP4 inhibitors.

Our group has studied pharmacogenetics of glucose-lowering drugs, including the effect of polymorphism of adiponectin, peroxisome proliferator-activated receptor gamma2 (PPAR $\gamma 2$ ), and lipin 1 genes on the efficacy of rosiglitazone [17-19], and effect of 
Citation: Kwon O, Choe EY, Choi Y, Kim HM, Wang HJ, et al. (2013) Discovery of DiPeptidyl Peptidase-4 Gene Variants and the Associations with Efficacy of Vildagliptin in Patients with Type 2 Diabetes - A Pilot Study. J Diabetes Metab S13: 006. doi:10.4172/2155-6156.S13-006

Page 5 of 6

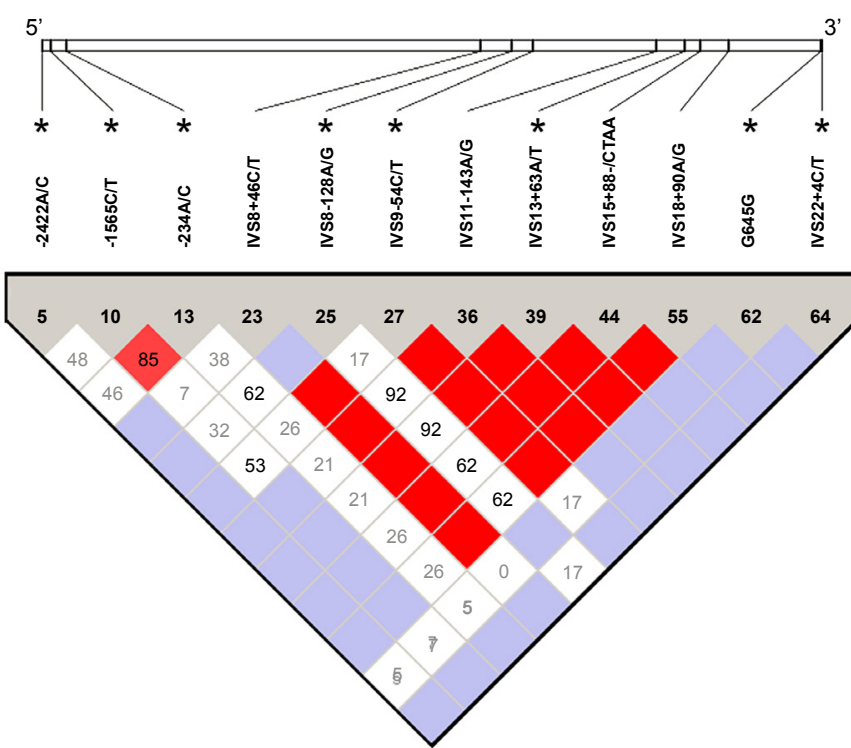

Figure 1: Linkage-disequilibrium structure of the dipeptidyl peptidase-4 gene in the Korean population. The upper diagram shows the relative position of single nucleotide polymorphisms (SNPs) discovered in this study as vertical lines. Asterisks point the tagging SNPs selected based on $r^{2}$ values. SNPs with an allele frequency below 0.05 were excluded from the structure.

\section{Luciferase assay}

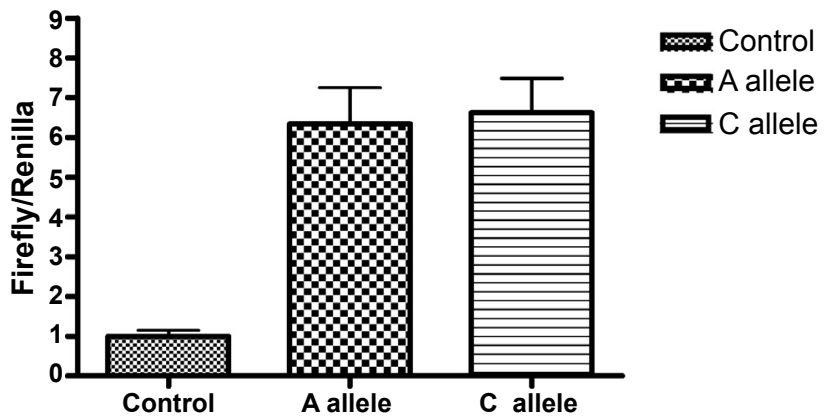

Figure 2: Measurements of DPP4 promoter activity according to regulatory SNP g.-234A/C. The transcriptional activity of the DPP4 promoter genotype of g.-234A/C was analyzed by luciferase-based reporter assay as detailed in Materials and Methods. Reporter vectors containing -507 to -31 region of the DPP4 gene were cloned from homozygote with each of the genotype. Promote activities were measured in Caco-2 cells $(n=3) 2$ days after transfection with the reporter plasmid. The reporter activity of each construct was compared with that of the control mock vector (pGL3-basic). Values are presented as means $\pm S D$.

polymorphism of perilipin gene on the side effects of rosiglitazone [20]. For the associations between DPP4 polymorphisms and metabolic diseases, several studies had been published. Aghili et al. [21] revealed that rs3788979 is associated with the risk of myocardial infarction in patients with atherosclerosis. Bouchard et al. [22] analyzed the association between DPP4 polymorphisms and cardiovascular disease risk factors from over a thousand samples in multi-stage study in 2009. Although 3 SNPs were associated with hyperglycemia/diabetes or high plasma triglyceride levels in the first stage, those associations failed to be replicated in stage 2 . This study group, however, revealed the methylation rate of DPP4 gene DNA of visceral adipose tissue (VAT) from severe obesity patients to be different between the genotypes for three DPP4 polymorphisms in 2011 [23], including the SNP associated with hyperglycemia/diabetes in the first stage of previous study. DPP4 polymorphisms were also studied for association with diseases other than metabolic disorders including periodontitis and major depressive disorders [24,25]. Rs 6741949 was shown to be associated with reduction in hippocampal volume, which is accelerated by Alzheimer's disease and vascular risk factors [26].

The major limitation of this study is the low number of enrolled subjects due to the nature of this research as a pilot study. The discovery in this study does not include normal healthy control data, which makes impossible to compare DPP4 polymorphisms of diabetic patients with that of healthy control. These points leave room for further pharmaco genetic study of DPP4 polymorphism in Korean population.

\section{Conclusion}

The current study analyzed the genotype of DPP4 gene in Korean diabetic populations. Our results do not support the notion that DPP4 polymorphisms are related with the glucose-lowering effect of vildagliptin. Further investigations with higher number of samples and comprehensive analysis are needed to reveal hidden associations between DPP4 polymorphisms and efficacy of DPP4 inhibitors/GLP-1 analogues in diabetic patients.

\section{Acknowledgements}

This work was financially supported by the "Kiturami" Faculty Research Assistance Program of Yonsei University College of Medicine (6-2012-0148, 6-2011-0085), Clinical Research Fund (4-2011-0912) and the National Research Foundation of Korea Grant funded by the Korean Government (MEST, Basic Research Promotion Fund; NRF-2010-013-E0008 and NRF-2012000891 to E.S. Kang).Gene scanning and haplotype analysis of DPP4 polymorphisms were supported by DNA Link, Inc.

\section{References}

1. Shaw JE, Sicree RA, Zimmet PZ (2010) Global estimates of the prevalence of diabetes for 2010 and 2030. Diabetes Res Clin Pract 87: 4-14.

2. Mokdad AH, Ford ES, Bowman BA, Dietz WH, Vinicor F, et al. (2003) Prevalence of obesity, diabetes, and obesity-related health risk factors, 2001. JAMA 289: 76-79.

3. American Diabetes Association (2013) Diagnosis and classification of diabetes mellitus. Diabetes Care 36 Suppl 1: S67-74.

4. Inzucchi SE, Bergenstal RM, Buse JB, Diamant M, Ferrannini E, et al (2012) Management of hyperglycemia in type 2 diabetes: a patient-centered approach: position statement of the American Diabetes Association (ADA) and the European Association for the Study of Diabetes (EASD). Diabetes Care 35: 1364-1379.

5. Jang YM, Kim DL (2011) Candidate dipeptidyl peptidase-4 inhibitors for the treatment of type 2 diabetes. Diabetes Metab J 35: 117-118.

6. Jeon HJ, Oh TK (2011) Comparison of vildagliptin-metformin and glimepiridemetformin treatments in type 2 diabetic patients. Diabetes Metab J 35: 529-535.

7. Drucker DJ (2006) The biology of incretin hormones. Cell Metab 3: 153-165.

8. Blüher M, Lübben G, Paschke R (2003) Analysis of the relationship between the Pro12Ala variant in the PPAR-gamma2 gene and the response rate to therapy with pioglitazone in patients with type 2 diabetes. Diabetes Care 26 : 825-831.

9. Adzhubei IA, Schmidt S, Peshkin L, Ramensky VE, Gerasimova A, et al (2010) A method and server for predicting damaging missense mutations. Nat Methods 7: 248-249.

10. Kumar P, Henikoff S, Ng PC (2009) Predicting the effects of coding nonsynonymous variants on protein function using the SIFT algorithm. Nat Protoc 4: 1073-1081.

11. Böhm SK, Gum JR Jr, Erickson RH, Hicks JW, Kim YS (1995) Human dipeptidy peptidase IV gene promoter: tissue-specific regulation from a TATA-less GC- 
Citation: Kwon O, Choe EY, Choi Y, Kim HM, Wang HJ, et al. (2013) Discovery of DiPeptidyl Peptidase-4 Gene Variants and the Associations with Efficacy of Vildagliptin in Patients with Type 2 Diabetes - A Pilot Study. J Diabetes Metab S13: 006. doi:10.4172/2155-6156.S13-006

Page 6 of 6

rich sequence characteristic of a housekeeping gene promoter. Biochem J 311 : 835-843.

12. Messeguer X, Escudero R, Farré D, Núñez O, Martínez J, et al. (2002) PROMO: detection of known transcription regulatory elements using speciestailored searches. Bioinformatics 18: 333-334.

13. Cartharius K, Frech K, Grote K, Klocke B, Haltmeier M, et al. (2005) Matlnspector and beyond: promoter analysis based on transcription factor binding sites. Bioinformatics 21: 2933-2942.

14. Wasserman WW, Sandelin A (2004) Applied bioinformatics for the identification of regulatory elements. Nat Rev Genet 5: 276-287.

15. Mentlein R, Gallwitz B, Schmidt WE (1993) Dipeptidyl-peptidase IV hydrolyses gastric inhibitory polypeptide, glucagon-like peptide-1(7-36)amide, peptide histidine methionine and is responsible for their degradation in human serum. Eur J Biochem 214: 829-835.

16. Deacon CF (2011) Dipeptidyl peptidase-4 inhibitors in the treatment of type 2 diabetes: a comparative review. Diabetes Obes Metab 13: 7-18.

17. Kang ES, Park SY, Kim HJ, Ahn CW, Nam M, et al. (2005) The influence of adiponectin gene polymorphism on the rosiglitazone response in patients with type 2 diabetes. Diabetes Care 28: 1139-1144.

18. Kang ES, Park SY, Kim HJ, Kim CS, Ahn CW, et al. (2005) Effects of Pro12Ala polymorphism of peroxisome proliferator-activated receptor gamma2 gene on rosiglitazone response in type 2 diabetes. Clin Pharmacol Ther 78: 202-208.

19. Kang ES, Park SE, Han SJ, Kim SH, Nam CM, et al. (2008) LPIN1 genetic variation is associated with rosiglitazone response in type 2 diabetic patients. Mol Genet Metab 95: 96-100.
20. Kang ES, Cha BS, Kim HJ, Kim HJ, Kim SH, et al. (2006) The $11482 \mathrm{G}>\mathrm{A}$ polymorphism in the perilipin gene is associated with weight gain with rosiglitazone treatment in type 2 diabetes. Diabetes Care 29: 1320-1324.

21. Aghili N, Devaney JM, Alderman LO, Zukowska Z, Epstein SE, et al. (2012) Polymorphisms in dipeptidyl peptidase IV gene are associated with the risk of myocardial infarction in patients with atherosclerosis. Neuropeptides 46: 367371.

22. Bouchard L, Faucher G, Tchernof A, Deshaies Y, Lebel S, et al. (2009) Comprehensive genetic analysis of the dipeptidyl peptidase-4 gene and cardiovascular disease risk factors in obese individuals. Acta Diabetol 46: 1321.

23. Turcot V, Bouchard L, Faucher G, Tchernof A, Deshaies Y, et al. (2011) DPP4 gene DNA methylation in the omentum is associated with its gene expression and plasma lipid profile in severe obesity. Obesity (Silver Spring) 19: 388-395.

24. Suzuki A, Ji G, Numabe Y, Ishii K, Muramatsu M, et al. (2004) Large-scale investigation of genomic markers for severe periodontitis. Odontology 92: 4347.

25. Schosser A, Gaysina D, Cohen-Woods S, Domenici E, Perry J, et al. (2011) A follow-up case-control association study of tractable (druggable) genes in recurrent major depression. Am J Med Genet B Neuropsychiatr Genet 156B 640-650.

26. Bis JC, DeCarli C, Smith AV, van der Lijn F, Crivello F, et al. (2012) Common variants at $12 q 14$ and $12 q 24$ are associated with hippocampal volume. Nat Genet 44: 545-551.
This article was originally published in a special issue, Type 2 Diabetes Mellitus- Disease, Diagnosis \& Treatment handled by Editors. Dr. Judit Bene, University of Pécs, Hungary; Eun Seok Kang, Yonsei University College of Medicine, Korea 